\title{
The Pathways From Parent Attachment to Adolescent Life Satisfaction Through Peer Attachment and Romantic Relationships
}

\author{
Seung Jin Kim ${ }^{1}$, Hyun-Sim Doh ${ }^{2}$, Woon Kyung Lee², Bokyung Park ${ }^{3}$ \\ Korea Institute of Child Care and Education, Seoul, Korea ${ }^{1}$ \\ Department of Child Development, Ewha Womans University, Seoul, Korea ${ }^{2}$ \\ Department of Education for Child Care, Kyungmin University, Uijeongbu, Korea ${ }^{3}$

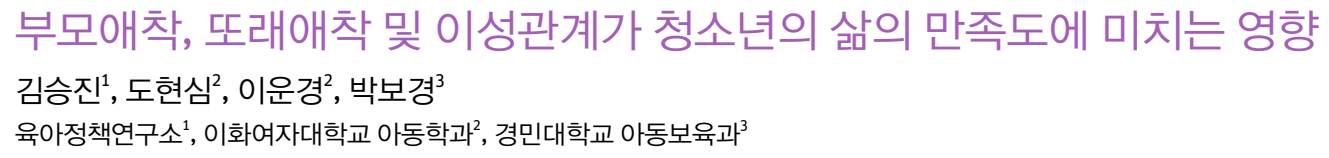

Objective: The purpose of this study was to examine pathways from parent attachment to adolescent life satisfaction and to determine the mediating roles of peer attachment and romantic relationships.

Methods: The participants were 221 high-school students (117 boys and 104 girls) living in Jeonnam province who had been in a romantic relationship for more than 3 months. The data were analyzed by $t$-tests, Pearson correlations, and SEM using SPSS 19.0 and Amos 18.0.

Results: Based on the research objective, 4 important results were summarized. First, father attachment and mother attachment had direct effects on adolescent life satisfaction. Second, mother attachment had an indirect effect on adolescent life satisfaction through peer attachment. Third, father attachment had an indirect effect on adolescent life satisfaction through romantic relationships. Fourth, mother attachment had an indirect effect on adolescent life satisfaction through peer attachment and romantic relationships.

Conclusion: The results from this study highlight the significant roles of parent attachment, peer attachment, and romantic relationships in adolescent life satisfaction. Specifically, the roles of father attachment and of romantic relationships in adolescent life satisfaction, which have seldom been explored in previous studies, should be emphasized. The findings can be used as an important basis for prospective research and practices for improving adolescent life satisfaction.

Keywords: adolescents, life satisfaction, parent attachment, peer attachment, romantic relationships

\begin{abstract}
서론
최근 우리나라의 교육, 경제, 과학 분야의 지표는 세계적으 로 상위 수준인 것에 비해, 아동 - 청소년의 삶의 질과 관련된

Corresponding Author: Hyun-Sim Doh, Department of Child Development, Ewha Womans University, 52, Ewhayeodae-gil, Seodaemun-gu, Seoul 03760, Korea

E-mail: simdoh@ewha.ac.kr
\end{abstract}

부분은 $\mathrm{OECD}$ 회원국 가운데 최하위 수준인 것으로 보고된 바 있다(M. W. Lee, 2016). 2009년부터 매년 유니세프의 어린 이 . 청소년 행복지수를 모델로 한 국제비교연구를 수행해오 고 있는 Yum, Kim과 Lee (2016)에 따르면, 우리나라 전국 초등

(C)The Korean Association of Child Studies

This is an Open Access article distributed under the terms of the Creative Commons Attribution Non-Commercial License (http:// creativecommons.org/licenses/by-nc/4.0) which permits unrestricted noncommercial use, distribution, and reproduction in any medium, provided the original work is properly cited. 
학교 4학년에서 고등학교 3학년까지의 아동.청소년이 보고한 '주관적 행복지수'는 2014년에 단 한차례 최하위를 벗어난 것 을 제외하고, 2015년을 포함하여 총 7년 동안 OECD 회원국 중 최하위를 기록하였다. 특히 2015년 조사에 의하면, 주관적 행복지수의 세부 항목 중 $\mathrm{OECD}$ 평균과 가장 차이를 보이는 항목은 '내 삶에 만족하는 정도'에 대한 응답이었으며 $(\mathrm{OECD}$ 평균: 85.19; 대한민국: 73.18), 조사대상 중학생과 고등학생이 자살충동 경험을 보고한 비율 또한 전체 학생의 $20 \%$ 를 초과 하였다. Ministry of Gender Equality and Family (2012)의 청소 년 종합실태조사에서도, 청소년의 $60.1 \%$ 는 스트레스에 시달 리고 있으며, 불안과 우울을 보고하는 비율도 $37.4 \%$ 에 이르는 것으로 나타나, 우리나라 청소년이 경험하는 전반적인 삶의 질 에 대한 학문적, 사회적 관심이 시급해 보인다. 청소년기에는 신체, 인지 및 사회정서 발달 영역 모두에서 급격한 변화가 일 어나며, 이 시기의 심리적 적응은 성인기의 심리적, 신체적 적 응에까지 영향을 미칠 수 있음을 고려할 때(L. Steinberg \& Silk, 2002), 우리나라 청소년이 주관적으로 인식하는 삶의 질에 영 향을 미치는 요인들을 이해하기 위한 노력이 절실히 요구된다.

삶에 대해 느끼는 총체적 만족감을 의미하는 삶의 만족도(life satisfaction; Suldo \& Huebner, 2004)는 주관적 안녕감(subjective well-being)의 중요한 구성요소로서(Diener \& Diener, 1995), 개인 이 인지하는 행복감을 평가하는 중요한 지표로 사용되어 왔다. 특히 삶의 만족도는 청소년의 신체적, 인지적, 사회정서적 적 응 및 발달과 연관성을 나타내어, 높은 삶의 만족도는 높은 학 교생활 적응도(H. I. Choi \& Moon, 2013), 목표의 성취(Gilman $\&$ Ashby, 2003), 사회에 대한 관심 및 공동체 의식(Gilman, 2001; S.-M. Kim \& Nam, 2011)과 관련된 반면에, 낮은 삶의 만족도는 낮은 학업성취와 건강수준(Langeveld, Koot, Loonen, HazebroekKampschreur, \& Passchier, 1996), 높은 빈도의 비행(Sohn, 2005) 등 청소년의 다양한 부적응적 발달과 연관된다고 보고되고 있다. 그러나 주관적 삶의 질 및 만족도에 대한 높은 사회적 관심과 성인의 삶의 만족도에 대한 축적된 연구결과에 비교하여(S. S. Lee, 2012; Lim, 2013; Locker, Clarke, \& Payne, 2000; Nam \& Kim, 2014), 청소년의 삶의 만족도에 대한 연구는 비교적 최근에 들 어서야 활발하게 수행되기 시작하였다.

선행 연구에서 나타난 삶의 만족도에 영향을 미치는 요인 은 크게 사회인구학적, 환경적, 그리고 인간관계적 측면으로 나누어 살펴볼 수 있는데, 이 가운데 가장 강력한 예측변인은 부모애착이나 또래애착과 같은 인간관계 관련 변인으로 보 고되는 경향이 있다(Armsden \& Greenberg, 1987; Nickerson \& Nagle, 2005). 즉, 선행 연구들은 사회인구학적 요인들이나 환
경적 요인들만으로 삶의 만족도를 설명하는 데 한계가 있으 며, 삶의 만족도는 개인이 경험하는 인간관계의 특성과 더 밀 접하게 관련될 수 있는 가능성을 제안하고 있다. 인간관계 적 측면 중에서도 부모애착은 삶의 만족도를 포함한 청소년 의 다양한 영역의 적응과 밀접한 관계가 있는 것으로 알려 져 왔다(Allen, McElhaney, Kuperminc, \& Jodl, 2004; Cotterell, 1992; McCormick \& Kennedy, 1994; Raja, McGee, \& Stanton, 1992; Rubin et al., 2004; Wainright, Russell, \& Patterson, 2004; Wilkinson, 2004).

부모와 안정적인 애착을 형성한 청소년은 새로운 환경에 잘 적응하고, 아동기에서 성인기로 넘어가는 과도기에 경험 하는 불안, 우울, 정서적 혼란 등을 덜 경험하였으며(Papini, Roggman, \& Anderson, 1991), 부모애착이 낮은 청소년 집단은 부모애착이 높은 청소년 집단보다 더 높은 수준의 스트레스를 경험하였다(Raja et al., 1992). 이 외에도 부모에 대한 애착수준 및 부모와 자신을 동일시하는 경향의 수준이 높은 청소년일수 록 전반적인 삶의 만족도가 높았으며(Man, 1991), 부모의 관 심을 더 높게 지각하는 청소년이 더 높은 현재 및 추후의 삶의 만족도를 보였다(C. Y.-W. Leung, McBride-Chang, \& Lai, 2004). 이와 같이, 부모애착과 청소년의 삶의 만족도 간에 일관되게 발견되는 밀접한 관계에 기초하건대, 청소년의 삶의 만족도 를 살펴보기 위해서 부모애착을 일차적으로 고려할 필요성이 제기된다. 동시에, 지금까지 부모애착이 청소년의 발달에 미 치는 영향을 살펴본 대부분의 연구들은 주 양육자로서 어머 니의 역할에 초점을 두었으며(e.g., Allen, Moore, Kuperminc, \& Bell, 1998; C. Y.-W. Leung et al., 2004), 부모애착의 삶의 만족도 에 대한 영향력을 살펴본 많은 연구들 역시 부애착과 모애착 을 구분하지 않은 경향이 있다(e.g., Greenberg, Siegel, \& Leitch, 1983; J.-P. Leung \& Leung, 1992; Raja et al., 1992). 그러나 부애 착과 모애착이 각각 청소년의 삶의 만족도에 미치는 영향력 을 살펴본 몇몇 선행 연구들이 부애착과 모애착 간 영향력의 차이 또는 양자 모두의 중요성을 보고하고 있어(S. M. Ahn \& Bang, 2013; Ko, 2008; Ma \& Huebner, 2008; Nickerson \& Nagle, 2004; Yoo, Lee, \& Kim, 2005), 청소년의 삶의 만족도와 관련해 서 부애착과 모애착 모두의 영향력을 탐색해 볼 필요성이 있 다.

한편, 삶의 만족도에 가장 큰 영향을 미치는 요인으로서 인간관계적 측면이 강조되는 것을 고려할 때(Ma \& Huebner, 2008), 청소년기 발달에 강조되는 다양한 인간관계의 측면들 에 관심을 기울일 필요가 있다. 무엇보다도 청소년기에는 자 아정체감과 독립성의 발달이 두드러지면서(W. A. Collins \& 
Repinski, 1994), 또래나 이성과 같은 동료와의 상호작용이 증 가하는 시기로, 이와 같은 평형적인 인간관계가 청소년의 적 응에 미칠 수 있는 영향력은 이전 시기에 비해 크다(Berndt, Hawkins, \& Jiao, 1999). 이는 청소년기의 애착관계가 주요 애 착 대상이었던 부모에서 보다 넓은 애착관계로 발달하는 것을 의미한다(Fraley \& Davis, 1997; Furman \& Wehner, 1994; Trinke $\&$ Batholomew, 1997). 다시 말하면, 부모는 여전히 중요한 안 정감의 근원이 될 수 있으나, 또래관계 및 이성관계가 청소년 의 애정 및 친밀함의 욕구를 충족시켜줄 수 있는 정도는 학령 기보다 증가한다. 이와 관련하여, 선행 연구들은 또래애착 및 이성관계가 삶의 만족도와 밀접한 관계가 있다고 보고한다. 청소년의 삶의 만족도에 미치는 애착관계들의 영향력을 살펴 본 연구에서, 또래애착은 부모애착과 함께 삶의 만족도를 잘 예측하였고(Ma \& Huebner, 2008), 긍정적 또래애착을 형성 한 청소년은 그렇지 않은 청소년에 비교하여 낮은 공격성 및 우울감을 보이며 더 높은 공감능력을 보였다(Laible, Carlo, \& Raffaelli, 2000).

또래관계에 비해 청소년의 이성관계가 발달에 미치는 영 향력에 대한 연구는 비교적 최근에 들어서야 수행되었으며 (Giordano, 2003), 청소년의 이성교제와 삶의 만족도 간의 관 련성을 살펴본 연구는 아직 드문 편이다. 국외 연구에 따르 면, 이성관계의 질은 대학생의 행복 및 높은 안녕감을 예측하 였으며(Demir, 2008; Moore \& Leung, 2002), 이성관계의 지나 친 몰입은 청소년의 정신건강과 부적 관계를 보였다(ZimmerGembeck, Siebenbruner, \& Collins, 2001). 또한, 청소년의 이성 관계에 관한 국내 연구에서 이성친구의 존재는 행동적 부적응 과 관련이 있는 것으로 보고된 바 있다(W.-B. Ahn, Lee, \& Kim, 2002). 부모, 또래, 이성을 포함한 다양한 애착 대상이 청소년 에게 미치는 상대적 영향력의 정도는 문화권에 따라 다를 뿐 만 아니라(Giordano, Cernkovich, \& Holland, 2003), 청소년의 이성관계에 대한 국내외 연구가 아직 초기단계임을 감안할 때, 우리나라 청소년의 이성관계와 삶의 만족도 간의 관계를 탐색해 볼 필요가 있다.

Bowlby $(1973,1979)$ 에 의하면, 생애 초기에 발달된 부모 와의 관계에 대한 정신적 표상(mental representation)은 부모 의 행동을 예측하고 해석하는 근거가 될 뿐 아니라, 또래관계 나 이성관계와 같이 또 다른 가까운 인간관계에 대한 표상 또 한 형성할 가능성이 있다. Furman과 Simon (1999)은 Bowlby의 이론을 확장한 '관점의 위계모델(hierarchical model of views)' 을 소개하며, 정신적 표상을 의미하는 관계에 대한 관점들 이 세 단계의 층으로 이루어진 위계적 구조를 이루며 서로 밀
접한 관련성을 가진다고 설명하였다. 세 층은 친밀한 관계 에 대한 일반적 관점(views of close relationships in general), 또 래관계 및 이성관계와 같은 관계 유형에 대한 관점(views of types of relationships), 특정 관계에 대한 관점(views of particular relationships)에 해당한다. 특히 세 가지 관점 가운데 가장 상 위층인 친밀한 관계에 대한 일반적 관점은 부모 애착의 질에 가장 중요한 영향을 받아 형성되는 것으로, 바로 아래에 위치 한 관계 유형에 대한 관점, 예컨대 또래관계나 이성관계에 대 한 관점에 영향을 미쳐서 또래 및 이성관계에서의 행동 및 관 계의 질에 차이를 나타낼 수 있다. 실제로 부모애착과 또래관 계 간의 관련성에 관해, 다수의 국내외 연구들이 부모와의 애 착 안정성과 아동 및 청소년의 또래관계의 질 간의 정적인 관 계를 보고하고 있다(Berlin \& Cassidy, 1999; J.-Y. Hong \& Doh, 2002; E. J. Kim \& Lee, 2009; Lieberman, Doyle, \& Markiewicz, 1999; Scheneider \& Younger, 1996). 이성관계는 부모-자녀관계 에서 보일 수 있는 애착의 유형(안정, 회피, 양가적 애착)이 비 슷하게 나타날 가능성이 높은데(Hazan \& Shaver, 1987), 부모 애착과 이성관계의 관련성에 대한 연구는 주로 성인 초기 및 성인기를 대상으로 수행되어 오다가(Barry, Madsen, Nelson, Caroll, \& Badger, 2009; Cha \& Chun, 2002; N. L. Collins \& Reed, 1990), 최근 들어 청소년을 대상으로 한 연구가 점차 증 가하는 추세이다. 일례로, 부모애착의 특성은 또래관계의 경 우와 마찬가지로 청소년의 이성관계, 결혼에 갖는 기대감, 이 성관계의 질이나 이성애착의 특성을 예측하였다(J. M. Kim \& Jang, 2008; S. J. Steinberg, Davila, \& Fincham, 2006).

앞서 언급한 관점의 위계모델(Furman \& Simon, 1999)에 따 르면, 또래애착과 이성관계는 동일한 층에 위치하고 있는 각 기 다른 관계 유형에 해당한다. 그러나 Furman과 Simon은 특 히 청소년의 이성관계에 관하여, 이성관계에 대한 관점의 상 위층인 친밀한 관계에 대한 일반적 관점 및 부모 애착으로만 청소년의 이성관계를 온전히 설명할 수 없다고 제안한 바 있 다. 특히 또래와의 친밀한 관계를 통해 발달할 수 있는 상호 호혜성 및 상호적 친밀감이 이성관계의 성립과 발전에도 중 요한 역할을 수행할 가능성이 높다고 설명하였으며, 이와 같 은 영향은 Furman과 동료들의 연구에서 지속적으로 확인되 었다(Furman, 1999; Furman, Simon, Shaffer, \& Bouchey, 2002; Furman \& Wehner, 1997). 실제로 또래애착이 높은 청소년은 자신의 이성관계 또한 긍정적으로 지각하는 경향이 있으며 (Connolly \& Johnson, 1996; Dunphy, 1963), 또래관계에서 높은 유능감을 보이는 청소년은 그렇지 않은 청소년보다 높은 질의 이성관계를 맺고 있다고 보고되었다(Roisman, Booth-LaForce, 
Cauffman, \& Spieker, 2009). 그러나 청소년의 또래애착과 이성 관계의 관련성을 다룬 경험적 연구는 여전히 부족한 편이다.

한편, 앞서 살펴본 바와 같이, 애착이론에 근거한 부모애착 과 또래애착 혹은 이성관계 간의 관계는 부모애착과 청소년의 삶의 만족도 사이에서 또래관계와 이성관계가 매개적 역할을 할 수행할 가능성을 가정하게 한다. 이러한 가정은 또한 청소 년의 또래관계와 삶의 만족도 간의 관계(Ma \& Huebner, 2008; Oberle, Schonert-Reichl, \& Zumbo, 2011) 및 이성관계와 삶의 만족도 간의 관계(Demir, 2008; Moore \& Leung, 2002)를 보고 한 선행 연구들에도 근거한다. 이를 직접적으로 살펴본 국내 외 연구는 거의 찾아보기 어려운 실정으로, 또래애착이 부모 애착과 여자 청소년의 삶의 만족도 간의 관계를 부분매개하였 던 Ma와 Huebner (2008)는 몇 안 되는 관련 연구에 속한다. 특 히 청소년의 이성관계가 발달 및 적응에 미치는 영향에 관한 연구가 아직 초기단계에 놓인 것과 마찬가지로, 청소년의 부 모애착, 또래애착, 이성관계와 삶의 만족도 간의 관계를 살펴 본 연구는 거의 전무하다.

종합하면, 삶의 만족도의 선행 변인으로서 부모애착, 또래 애착 및 이성관계 간의 연결성은 다수의 이론적, 경험적 선행 연구들을 통해 제안된 바 있고(Giordano, 2003), 특히 관점의 위계모델(Furman \& Simon, 1999)에 근거하여 부모애착이 또 래애착 및 이성관계에 미치는 영향, 또래애착이 이성관계에 미치는 영향을 가정해볼 수 있다. 또한 삶의 만족도에 있어 부 모애착이 또래애착과 이성관계를 통해 청소년의 삶의 만족도 에 이르는 경로 또한 유추해 볼 수는 있으나, 네 변인 간의 구 조를 동시에 살펴본 경험적 연구는 찾아보기 어렵다. 한편 선 행 연구들은 또래애착 및 이성관계와 관련하여 각각 학령기와 성인기를 연구대상의 주요 발달단계로 선정하고 있어, 위 변 인들 간의 관계를 청소년을 대상으로 살펴볼 필요가 있다. 이 에 본 연구에서는 고등학교에 재학 중인 청소년을 대상으로 하여 부모애착이 청소년의 삶의 만족도에 미치는 직접적 영향 을 비롯하여 또래애착과 이성관계를 통한 간접적 영향을 살펴 보았다. 본 연구에서 선정한 연구문제와 연구모형은 다음과 같다(Figure 1).

\section{연구문제 1}

부모애착, 또래애착 및 이성관계는 청소년의 삶의 만족도에 어떠한 경로로 영향을 미치는가?

1.1. 부애착 및 모애착은 청소년의 삶의 만족도에 직접적 영향을 미치는가?
1.2. 부애착 및 모애착은 또래애착을 통해 청소년의 삶의 만족도에 간접적 영향을 미치는가?

1.3. 부애착 및 모애착은 이성관계를 통해 청소년의 삶의 만족도에 간접적 영향을 미치는가?

1.4. 부애착 및 모애착은 또래애착에, 또래애착은 이성관 계에, 그리고 이성관계는 청소년의 삶의 만족도에 영향을 미침으로써 부애착 및 모애착은 청소년의 삶의 만족도에 간접적 영향을 미치는가?

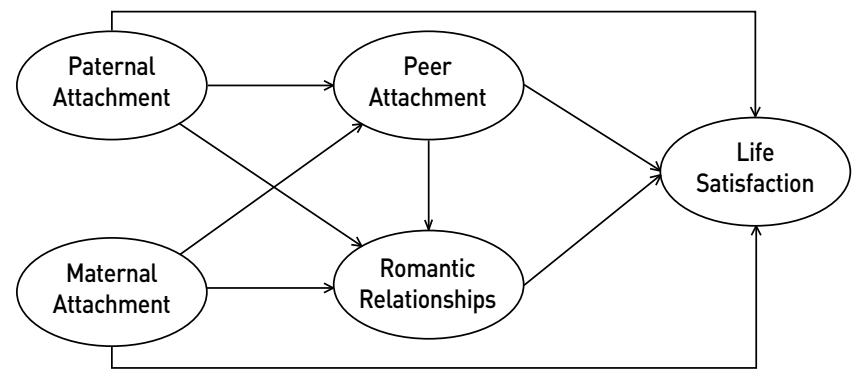

Figure 1. Pathways from paternal and maternal attachment to adolescent life satifaction through peer attachment and romantic relationships.

\section{연구방법}

\section{연구대상}

본 연구의 대상은 전라남도 소재의 일반계 남녀공학 고등학교 3 곳에 재학 중인 청소년 가운데 3 개월 이상 이성교제 중인 221 명의 남녀 청소년이다. 고등학생 시기는 학업 스트레스를 비교 적 더 많이 느끼고 대학 진학에 대한 부담감을 느껴 중학생보 다 삶의 만족에 있어서 취약하다는 점(Yoo, Lee, \& Jung, 2006) 과 여자 고등학교에 다니는 청소년 보다 남녀공학에 재학 중인 청소년이 이성관계를 맺는 경우가 더 많다는 연구결과(Chang, Lee, \& Jun, 2002)에 기초하여 남녀공학 고등학교에 재학 중인 청소년을 연구대상으로 선정하였다. 또한 이성교제 기간과 관 련하여 많은 연구들이 기간에 제한을 두지 않았으나, 본 연구 에서는 관계 형성을 위해 필요하다고 여겨지는 최소한의 기간 으로서 3 개월 이상 교제한 청소년들을 대상으로 하였다.

본 연구대상의 사회인구학적 특성을 살펴보면, 청소년의 성별은 남학생이 117 명(52.9\%), 여학생이 104 명(47.1\%)이었 으며, 평균 연령은 18 세이다. 출생순위는 둘째가 104 명(47\%) 
으로 가장 많았으며 그 다음으로 첫째는 77 명 $(34.8 \%)$, 셋째는 32 명(14.5\%) 순이었다. 아버지와 어머니의 연령은 45-49세가 각각 125 명(56.6\%)과 122 명(55.2\%)으로 가장 많았으며, 교육 수준은 아버지와 어머니 모두 고등학교를 중퇴하거나 졸업한 경우가 각각 107 명(48.4\%)과 142 명(64.3\%)으로 가장 많았다. 부모의 직업을 살펴보면, 아버지의 경우 회사원, 은행원, 공무 원이 118 명(53.4\%)으로 가장 많았고 어머니의 경우에는 가정 주부가 99명(44.8\%)으로 가장 많았다. 연구대상 청소년의 이 성교제 기간은 대체로 3 개월 2년 이상으로 다양하게 분포되 고 있으나, 3-6개월이 107명(48.4\%)으로 가장 많았고, 1-2년 미만이 46명(20.8\%), 2년 이상이 30명(13.6\%)이었으며, 평균 교제 기간은 약 7 개월이었다.

\section{조사도구}

본 연구의 조사도구는 청소년이 지각하는 부애착과 모애착을 포함한 부모애착, 또래애착, 이성관계 및 삶의 만족도를 측정 하기 위한 4 가지 척도로 구성된다. 모든 척도는 청소년에 의해 보고되었으며, 각 척도의 문항은 거의 그렇지 않다(1점), 그렇 지 않은 편이다(2점), 그런 편이다(3점), 매우 그렇다(4점)의 4 점 Likert식 척도이다.

\section{부모애착}

부모애착은 Armsden과 Greenberg (1987)의 부모애착 및 또래 애착 척도(Inventory of Parent and Peer Attachment [IPPA])의 개 정본(IPPA-R)을 번안.수정한 $\mathrm{Ok}$ (1998)의 척도를 사용하여 측 정하였다. 본 척도는 아동 및 청소년을 대상으로 부모에 대한 인지적 - 정서적 - 행동적 차원의 애착 정도를 측정하기 위한 것으로 신뢰감( 10 문항), 의사소통(9문항), 소외감(6문항)의 3 가지 하위요인으로 구성된다(총 25문항). 각 요인별 문항의 예 로는, 신뢰감의 경우 "우리 아버지(어머니)는 내 판단을 신뢰 하신다.", "우리 아버지(어머니)는 내 감정을 존중해 주신다." 등을, 의사소통의 경우 "우리 아버지(어머니)는 나의 어려움 을 이야기하도록 격려해 주신다.", "나는 아버지(어머니)에게 나의 어려움과 근심거리에 대해 말씀 드린다.” 등을, 그리고 소외감의 경우, "나는 아버지(어머니)와 있을 때 쉽게 기분이 나빠진다.", "나는 아버지(어머니)로부터 별 관심을 받지 못한 다." 등을 들 수 있다. 본 연구에서는 하위요인 중 신뢰감과 소 외감 요인에서 신뢰도를 낮추는 각 1 문항씩 2 문항을 제외하 였다. 각 요인별 Cronbach's $\alpha$ 를 산출한 결과, 부애착은 신뢰감
.88 , 의사소통 .90 , 소외감 .72이었고, 모애착은 신뢰감 .87 , 의 사소통 . 90 , 소외감 .71이었다. 본 연구에서는 구조방정식 모 형 분석 시 부모애착을 측정하는 하위요인들의 방향성을 일치 시키기 위해 소외감 요인의 문항들을 역채점하였다.

\section{또래애착}

청소년의 또래관계는 Armsden과 Greenberg (1987)의 부모애착 및 또래애착 척도(IPPA)의 개정본(IPPA-R)을 번안 · 수정한 $\mathrm{Ok}$ (1998)의 척도에서 또래애착 부분을 사용하여 측정하였다. 본 척도는 아동 및 청소년을 대상으로 친구에 대한 인지적 - 정서 적 - 행동적 차원의 애착 정도를 측정하는 것으로 신뢰감(10문 항), 의사소통(8문항), 소외감(7문항)의 3 가지 하위요인, 총 25 문항으로 구성된다. 문항의 예를 들면, 신뢰감의 경우, "친구들 은 내가 어떤 일로 기분이 상했을 때 알아차린다.", "내 친구들 은 내가 말하려고 하는 것을 귀담아 듣는다." 등으로 구성되어 있고, 의사소통의 경우, "내게 걱정되는 일이 있을 때, 친구들의 의견을 받아들이고 싶다.", "나의 친구들은 나를 이해한다." 등 이 있으며, 소외감의 경우, "내 친구들은 내가 요즘 어떤 일을 겪는지 이해하지 못한다.", “친구들과 함께 내 문제에 관해 이 야기할 때, 나 자신이 수치스럽고 바보 같다고 생각된다.” 등으 로 구성되어 있다. 본 연구에서는 하위요인 중 소외감 요인에 서 신뢰도를 낮추는 1 문항을 제외하였다. 각 요인별 Cronbach's $\alpha$ 를 산출한 결과, 신뢰감 .85, 의사소통 .75, 소외감 .75로 나타 났다. 본 연구에서는 구조방정식 모형 분석 시 또래애착을 측 정하는 하위요인들의 방향성을 일치시키기 위하여 소외감 요 인의 문항들을 역채점하였다.

\section{이성관계}

이성관계의 질을 측정하기 위하여 Bowden (1977)의 결혼만족 도 척도(Marital Satisfaction Scale [MSS])를 I. S. Lee와 Yoo (1986) 가 국내 상황과 미혼 남녀 관계의 질을 측정하기에 적합하도 록 재구성한 척도를 사용하였다. 이 척도는 단일요인으로서, 총 11 문항으로 구성되어 있다. 문항내용으로는 "내 남자친구 (여자친구)는 되도록 나를 편하게 해주려고 한다." "나는 남자 친구(여자친구)를 항상 신뢰할 수 있다." 등이 포함되어 있다. 부정적 내용의 문항은 역채점하였으며, 점수가 높을수록 이성 관계의 질, 즉 이성에 대한 애정, 만족도, 헌신의 정도가 높음 을 의미한다. Cronbach's $\alpha$ 는 . 88 이었다. 


\section{삶의 만족도}

삶의 만족도는 Diener, Emmons, Larsen과 Griffins (1985)의 삶 의 만족도 척도(The Satisfaction with Life Scale)를 Jo와 Cha (1998)가 번안한 것을 사용하여 측정하였다. 본 척도는 단일요 인으로서 총 5 문항으로 구성되어 있다. 문항내용으로는 "나는 대체로 내 이상에 가까운 생활을 하고 있다.", "나는 나의 삶 에 대해 만족한다." 등이 포함되며, 점수가 높을수록 청소년이 자신의 삶에 만족하고 있음을 의미한다. 본 연구에서 산출된 Cronbach's $\alpha$ 는 .80이었다.

\section{조사절차 및 자료분석}

본 조사에 앞서 본 연구의 네 가지 척도 가운데 이성관계의 질 을 측정하기 위한 I. S. Lee와 Yoo (1986)의 척도를 청소년에게 사용가능한지 확인하기 위해 고등학교 1,2 학년에 재학 중인 30 명의 청소년들을 대상으로 예비조사를 실시하였다. 그 결 과, 고등학생이 문항내용을 이해하고 질문지를 작성하기에 어 려움이 없음을 확인하였다.

본 조사는 2014년 7월 중 약 3주간에 걸쳐 실시하였다. 전 라남도에 위치한 3곳의 일반계 남녀공학 고등학교장의 동의 하에 본 연구자가 각 학교에 방문하여 각 학년의 주임교사들 에게 연구목적 및 질문지 작성 시 유의사항을 상세히 설명하 고, 담임교사들이 학생들에게 질문지를 배부하여 조사한 후 회수하였다. 배부된 1300 부의 질문지 가운데 1280 부가 회수 되었다( $98 \%$ 의 회수율). 회수된 질문지 가운데 이성교제를 하 지 않는 경우(1055부)와 이성교제 기간이 3개월 미만인 경우 (4부)를 제외한 223 부 중 응답이 불성실한 경우( 2 부)를 제외하 여 총 221 부를 분석에 사용하였다.

수집된 자료는 SPSS 19.0 (IBM Co., Armonk, NY)와 AMOS 18.0 (IBM Co., Armonk, NY)을 사용하여 분석하였다. 먼저, SPSS 19.0을 이용해 예비분석으로 연구대상자의 사회인구학 적 특성을 살펴보기 위해 빈도와 백분율을 산출하고 연구변인 들의 평균 및 표준편차를 구하였으며, 연구변인들에서의 성차 를 알아보기 위해 $t$ 검정을 실시하였다. 조사도구의 신뢰도를 확인하기 위해 Cronbach's $\alpha$ 값을 산출하였으며, 측정변인들 간의 상관관계를 알아보기 위해 Pearson의 적률상관계수를 산 출하였다. 다음으로, 본 연구의 연구문제인 청소년의 부애착 과 모애착을 포함한 부모애착과 또래애착 및 이성관계, 청소 년의 삶의 만족도 간의 구조적 관계를 확인하기 위해 AMOS 18.0 을 이용하여 구조방정식 모형 분석을 실시하였다. 잠재
변수들이 측정변수들을 잘 설명하는지를 확인하기 위해 청소 년의 부모애착, 또래애착 및 이성관계가 청소년의 삶의 만족 도에 미치는 경로모형의 측정모형 타당성을 검증하는 확인적 요인분석(confirmatory factor analysis [CFA])을 실시하였다. 이 를 위해 측정모형을 구성하여 적합도를 검증하고 최대우도법 (maximum likelihood method [MLM])을 사용하여 요인부하량 을 분석한 후 구조모형 분석을 하였다. 또한 경로의 효과성을 분석하고 매개효과의 유의성을 평가하기 위해 부트스트래핑 방법(bootstrapping)을 실시하였다.

\section{연구결과}

\section{예비분석}

본 분석을 실시하기에 앞서 연구변인인 부애착과 모애착을 포 함한 부모애착, 또래애착, 이성관계 및 청소년의 삶의 만족도 에서의 성차를 살펴보았다. 그 결과, 모든 변인들 가운데 또래 애착의 소외감 요인에서만 유의한 성차가 나타나 $(t=2.53, p$ $<.05)$, 남학생 $(M=2.06, S D=0.33)$ 이 여학생 $(M=1.94, S D=$ 0.37)보다 또래와의 관계에서 소외감을 더 많이 느끼는 것으 로 보고하였다. 이와 같이 연구변인들에서의 성차가 거의 발 견되지 않아 본 분석은 전체 청소년을 대상으로 실시되었다.

\section{측정변인들 간 상관관계}

부모애착, 또래애착, 이성관계 및 청소년의 삶의 만족도 간의 상관관계를 살펴본 결과, 연구변인의 하위요인들 간에 모두 유의한 상관이 발견되었다. 이를 구체적으로 살펴보면 다음과 같다(Table 1).

첫째, 부모애착과 청소년의 삶의 만족도 간의 상관관계와 관련하여, 부애착 및 모애착의 하위요인들은 삶의 만족도와 유의한 정적 $(r s=.38, .41, p<.001)$ 혹은 부적 $(r s=-.35,-.40, p$ <.001) 상관을 보였다. 즉, 청소년들은 부모에게 신뢰감을 가 지고 편안하게 의사소통을 하며 소외감을 덜 느낄수록 자신의 삶에 만족한다고 보고하였다. 둘째, 또래애착의 하위요인들 은 청소년의 삶의 만족도와 유의한 정적 $(r=.37, p<.001)$ 상 관과 부적 $(r=-.33, p<.001)$ 상관을 보였다. 즉, 청소년들이 또 래에게 신뢰감을 가지고 편안하게 의사소통을 하며 소외감을 덜 느낄수록 자신의 삶에 만족하는 것으로 나타났다. 셋째, 이 성관계는 청소년의 삶의 만족도와 유의한 정적 상관을 보여 $(r$ 
Table 1

Correlations Among Adolescent Parent Attachment, Peer Attachment, Romantic Relationships and Life Satisfaction

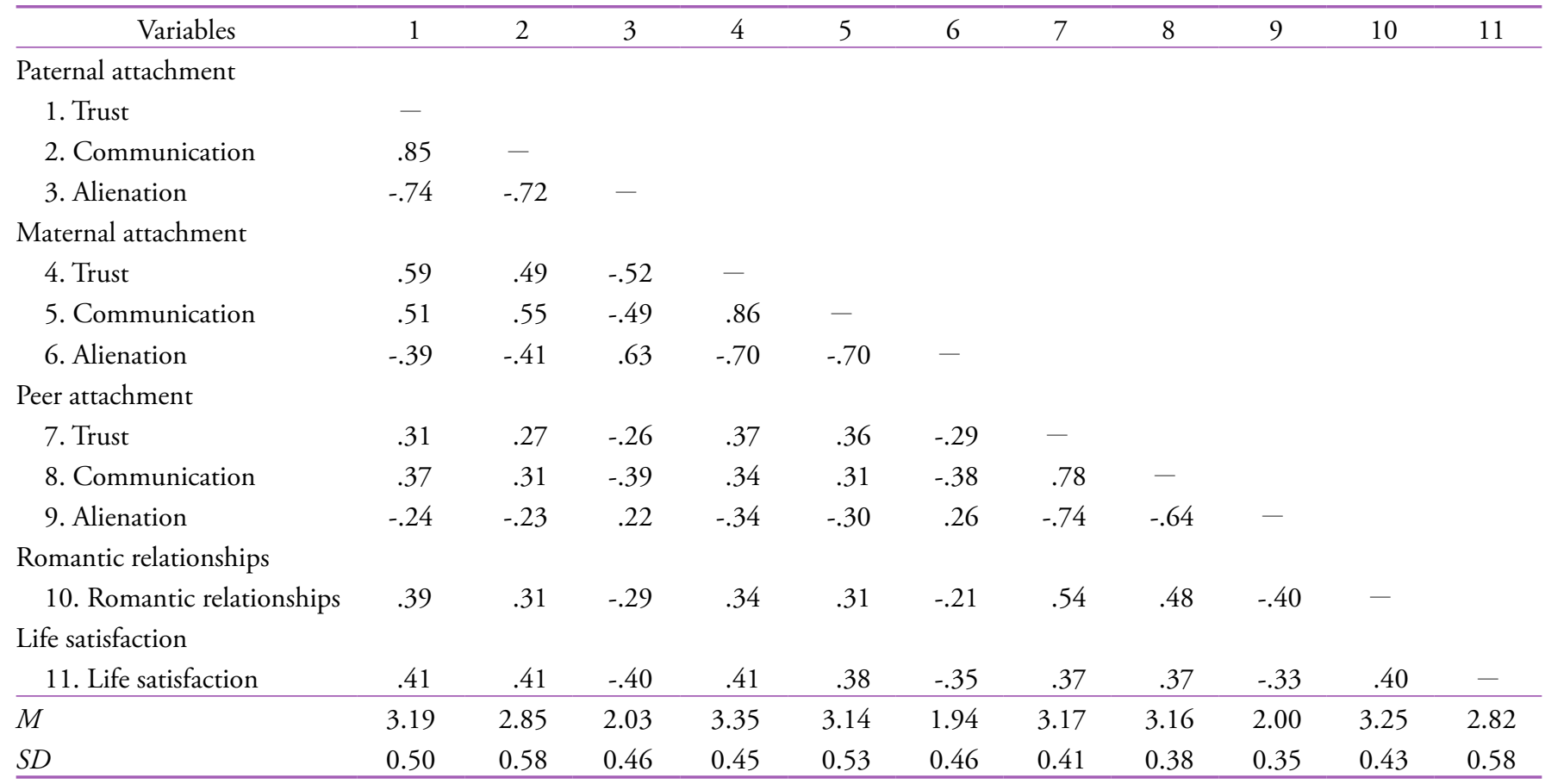

Note. $N=221$. All correlation coefficients were significant at $p<.001$.

$=.40, p<.001)$, 청소년들은 이성관계의 질을 높게 지각할수록 자신의 삶에 만족하였다. 넷째, 부모애착의 하위요인들은 또 래애착의 하위요인들과 유의한 정적 $(r s=.22 \sim .37, p<.001)$ 혹은 부적 $(r s=-.39 \sim-.23, p<.001)$ 상관을 보여, 청소년들은 부모에게 신뢰감을 가지고 편안하게 의사소통을 하며 소외감 을 덜 느낄수록 또래에게 신뢰감을 가지고 편안하게 의사소통 을 하며 소외감을 덜 느꼈다. 다섯째, 부모애착의 하위요인들 은 이성관계와 유의한 정적 $(r s=.31 \sim .39, p<.001)$ 혹은 부적 $(r s=-.21,-.29, p<.001)$ 상관을 보였다. 즉, 청소년들은 부모 에게 신뢰감을 가지고 편안하게 의사소통을 하며 소외감을 덜 느낄수록 이성관계의 질을 높게 지각하는 것으로 나타났다. 마지막으로, 또래애착의 하위요인들은 모두 청소년의 이성관 계와 유의한 정적 $(r s=.48, .54, p<.001)$ 혹은 부적 $(r=-.40, p$ $<.001)$ 상관을 보여, 청소년들은 또래에게 신뢰감을 가지고 편안하게 의사소통을 하며 소외감을 덜 느낄수록 이성관계의 질을 높게 지각하였다.

\section{측정모형 분석}

연구모형의 구조적 관계를 검증하기에 앞서, 측정변인들이 잠
재변인인 청소년의 부모애착, 또래애착, 이성관계 및 삶의 만 족도를 적절히 설명하는지를 판단하기 위해 확인적 요인분석 (CFA)을 실시하였다. 확인적 요인분석의 모수추정방식은 최 대우도법(MLM)을 사용하였다. 이는 모든 변수들이 다변량 정규분포를 따른다고 가정하고 요인의 적재치를 계산하는 방 법이다.

초기 모형을 살펴본 결과, 측정모형의 적합도 지수는 $\chi^{2}$ $=204.150(d f=36, p<.001), \chi^{2} / d f=5.671$, NFI $=.895$, TLI $=$ $.864, \mathrm{CFI}=.911, \mathrm{RMSEA}=.146$ 으로 나타났다. 적합도 지수에 관한 기준과 관련하여, $\chi^{2}$ 의 값이 유의하지 않아야 모델의 적 합도가 좋다고 판단할 수 있으나, $\chi^{2}$ 값은 표본크기의 영향을 받기 때문에 다른 적합도 지수도 함께 고려하여 적합도를 평 가하는 것이 바람직하다(G. S. Kim, 2011). 다른 적합도 지수 들 중 NFI, TLI, CFI는 .90을 넘어야 좋은 적합도라고 할 수 있 고, RMSEA는 .05 이하이면 좋은 적합도 .08 이하이면 괜찮은 적합도라고 할 수 있다(S. Hong, 2000). 이 기준에 근거할 때, 본 연구의 초기모형은 적합도의 기준을 충족하지 못하여 적절 하지 않은 것으로 판단되었다(Table 2). 수정지수(Modification Index [MI])가 9 이상인 경우 오차변량 간 상관이 높으므로 (Fassinger, 1987), 이론적으로 설명이 가능한 경우에 공분산 
경로를 설정할 수 있어(G. S. Kim, 2011), 모형 수정을 위하여 수정지수를 살펴보았다. 그 결과, 부애착의 하위요인인 소외 감(e3)과 모애착의 하위요인인 소외감(e6) 간 수정지수( $\mathrm{MI}=$ 73.295)가 가장 크게 나타나, 양자 간의 공분산을 설정하였다 (수정모형 1). 이는 두 변인 간의 높은 상관관계를 보고한 선행 연구결과(Y.-H. Kim, Lee, \& Kim, 2009)에 근거한 것이다. 수정 모형은 초기 모형보다 적합도가 향상되었으나, 부애착의 하위 요인인 의사소통(e2)과 모애착의 하위요인인 신뢰감(e4) 간의 수정지수(MI = 34.530)가 크게 나타나, 두 변인 간의 높은 상 관관계를 보고한 연구결과(Y.-H. Kim et al., 2009)에 근거하여 공분산을 추가로 설정하였다(수정모형 2). 그 결과, RMSEA의 값이 .07로 나타나.08 이하이면 괜찮은 적합도라는 기준을 충 족하게 되어, 수정모형 2 를 최종모형으로 채택하였다. 최종 모 형의 적합도 지수는 $\chi^{2}=71.105(d f=34, p<.001), \mathrm{NFI}=.963$,
$\mathrm{TLI}=.968, \mathrm{CFI}=.980, \mathrm{RMSEA}=.070$ 으로 적절한 수준의 적 합도를 보였다(Table 2).

잠재변인에서 측정변인 간의 표준화된 회귀계수 값들은 .786 .957로, C. R. (Critical Ratio)값 또한 모두 유의수준 .001 에서 유의하였다(Table 3, Figure 2). 이는 측정변인이 잠재변인 의 개념을 잘 설명하고 있음을 의미한다. 따라서 해당 모형을 채택하여 후속 분석을 실시하였다.

\section{구조모형 분석}

부애착과 모애착을 포함한 부모애착, 또래애착 및 이성관계가 청소년의 삶의 만족도에 어떠한 경로로 여향을 미치는지를 확 인하기 위해 구조방정식을 이용해 분석을 실시하였다. 먼저, 연구모형의 경로를 검증하였고, 부트스트래핑 방법을 사용하

Table 2

Fit Indices of the Measurement Model

\begin{tabular}{lcccccccc}
\hline \multicolumn{1}{c}{ Model } & $\chi^{2}$ & $d f$ & $\chi^{2} / d f$ & NFI & TLI & CFI & GFI & RMSEA (LO90 HI90) \\
\hline Initial model & $204.150^{* * *}$ & 36 & 5.671 & .895 & .864 & .911 & .866 & $.146(.127 \sim .165)$ \\
Modified model 1 & $114.355^{* * *}$ & 35 & 4.854 & .941 & .934 & .958 & .919 & $.102(.081 \sim .123)$ \\
Modified model 2 & $71.105^{* * *}$ & 34 & 2.091 & .963 & .968 & .980 & .949 & $.070(.047 \sim .093)$ \\
\hline
\end{tabular}

Note. $N=221$. NFI = normed fit index; TLI = Tucker-Lewis index; CFI = comparative fit index; GFI = goodness-of-fit index; RMSEA = root mean square error of approximation. For modified model 1, e3 and e6 in the initial model were allowed to correlate; For modified model 2, e2 and e4 in the modified model 1 were allowed to correlate.

${ }^{* * *} p<.001$.

Table 3

Factor Loadings for the Measurement Model

\begin{tabular}{|c|c|c|c|c|}
\hline Variables & $B$ & $\beta$ & $S E$ & C.R. \\
\hline \multicolumn{5}{|l|}{ Paternal attachment } \\
\hline Trust & 1.000 & .954 & - & - \\
\hline Communication & 1.095 & .897 & .046 & $23.594^{* * *}$ \\
\hline \multicolumn{5}{|l|}{ Maternal attachment } \\
\hline Trust & 1.000 & .957 & - & - \\
\hline Communication & 1.108 & .910 & .045 & $24.537^{* * *}$ \\
\hline \multicolumn{5}{|l|}{ Peer attachment } \\
\hline Trust & 1.000 & .955 & - & - \\
\hline Communication & .799 & .816 & .048 & $16.792^{* * *}$ \\
\hline Alienation & .815 & .840 & .046 & $17.770^{* * *}$ \\
\hline \multicolumn{5}{|l|}{ Romantic relationships } \\
\hline Romantic relationships & .379 & .938 & - & - \\
\hline
\end{tabular}

Note. $N=221$. Scores of alienation were reversely coded in order to match the direction with parent attachment and peer attachment. ${ }^{* * *} p<.001$. 


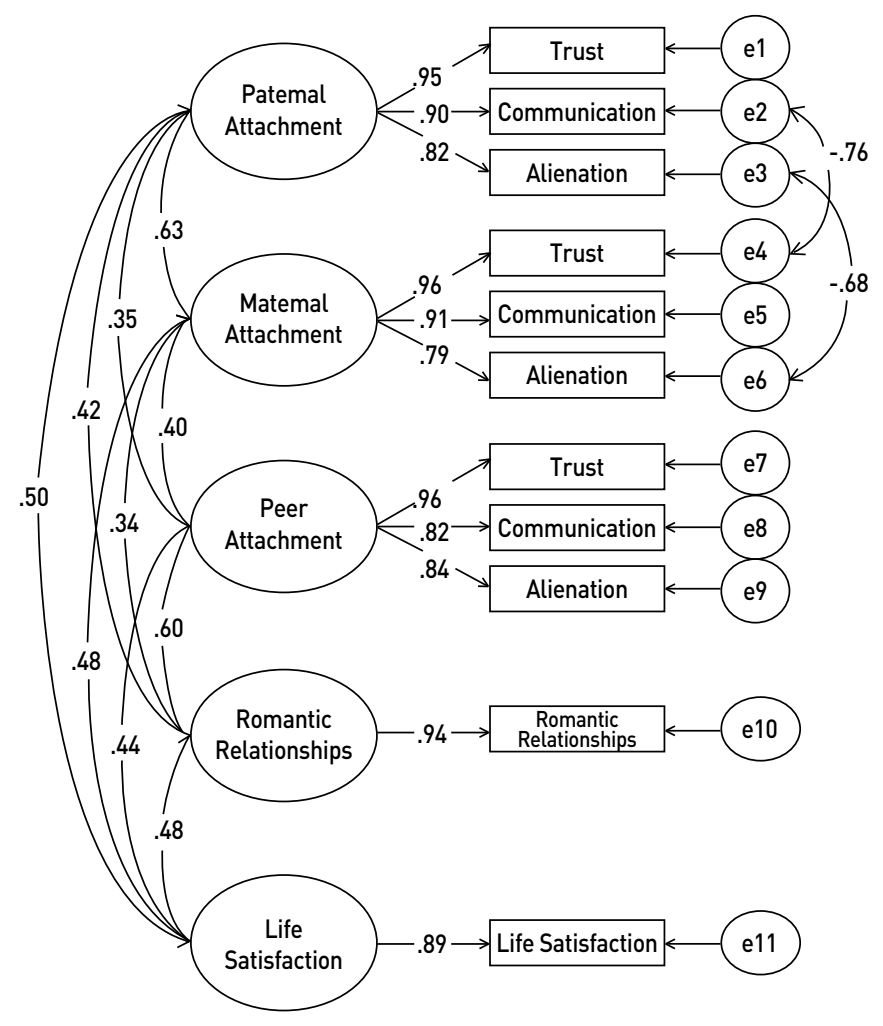

Figure 2. Factor loadings of the measurement model. Scores of alienation were reversely coded to match the direction of parent attachment and peer attachment.

관계가 긍정적이었으며, 또래애착이 긍정적일수록 청소년의 삶의 만족도가 높았다. 셋째, 부모애착이 이성관계를 통해 청 소년의 삶의 만족도에 영향을 미치는 경로와 관련하여, 부애 착과 모애착 가운데 부애착만이 청소년의 이성관계 $(\beta=.25, p$
<.01)에 유의한 영향을 미쳤으며, 이성관계는 청소년의 삶의 만족도 $(\beta=.18, p<.05)$ 에 유의한 영향을 미쳤다. 즉, 아버지 에 대한 애착이 긍정적인 청소년일수록 높은 질의 이성관계를 경험한다고 지각하였으며, 이는 청소년의 높은 삶의 만족도 로 연결되었다. 마지막으로, 부모애착이 또래애착과 이성관계 를 통해 청소년의 삶의 만족도에 영향을 미치는 경로와 관련 하여, 부애착과 모애착 가운데 모애착만이 또래애착 $(\beta=.30, p$ <.001)에, 또래애착은 이성관계 $(\beta=.49, p<.001)$ 에, 이성관계 는 삶의 만족도 $(\beta=.18, p<.05)$ 에 유의한 영향을 미쳤다. 즉, 어머니에 대한 애착이 긍정적인 청소년일수록 자신의 또래관 계를 긍정적으로 보고하였으며, 또래애착이 높은 청소년은 이 성관계의 질을 높게 지각하여 결과적으로 높은 삶의 만족도를 보고하였다.

이어서, 각 변인 간의 경로에서의 구조적 관계를 검증하고 자 부모애착, 또래애착 및 이성관계가 청소년의 삶의 만족도 에 미치는 직·간접효과와 총 효과를 살펴보았다(Table 5). 그 결과, 청소년의 삶의 만족도에 영향을 미치는 변인들의 총 효 과는 부애착 $(\beta=.295, p<.01)$, 모애착 $(\beta=.240, p<.01)$, 또래 애착 $(\beta=.237, p<.01)$, 이성관계 $(\beta=.176, p<.01)$ 순으로 나타 나, 부애착이 청소년의 삶의 만족도에 가장 큰 영향을 미치는 것으로 확인되었다. 또한 청소년의 또래애착에는 모애착 $(\beta=$ $.303, p<.01)$ 이 유의한 영향을 미쳤으며, 청소년의 이성관계 에는 또래애착 $(\beta=.485, p<.01)$ 과 부애착 $(\beta=.249, p<.01)$ 순 으로 영향을 미쳐 또래애착의 영향력이 가장 큰 것으로 나타 났다. 끝으로, 부트스트래핑을 통해 부모애착과 청소년의 삶 의 만족도 간의 관계에서 또래애착과 이성관계의 간접효과의 유의성을 확인해본 결과, 부애착 $(\beta=.082, p<.01)$ 과 모애착 $(\beta=.066, p<.01)$ 은 또래애착과 이성관계를 통해 청소년의 삶

Table 4

Path Estimates of Latent Variables

\begin{tabular}{|c|c|c|c|c|c|c|}
\hline \multicolumn{3}{|c|}{ Path of latent variables } & \multirow{2}{*}{$\begin{array}{c}B \\
.257\end{array}$} & \multirow{2}{*}{$\begin{array}{c}\beta \\
.213\end{array}$} & \multirow{2}{*}{$\begin{array}{l}S E \\
.097\end{array}$} & \multirow{2}{*}{$\begin{array}{c}\text { C.R. } \\
2.640^{* *}\end{array}$} \\
\hline Paternal attachment & $\rightarrow$ & Life satisfaction & & & & \\
\hline Maternal attachment & $\rightarrow$ & Life satisfaction & .228 & .174 & .105 & $2.170^{*}$ \\
\hline Romantic relationships & $\rightarrow$ & Life satisfaction & .236 & .176 & .096 & $2.456^{*}$ \\
\hline Paternal attachment & $\rightarrow$ & Peer attachment & .129 & .157 & .072 & 1.788 \\
\hline Paternal attachment & $\rightarrow$ & Romantic relationships & .224 & .249 & .068 & $3.272^{* *}$ \\
\hline Maternal attachment & $\rightarrow$ & Romantic relationships & -.032 & -.032 & .076 & -0.415 \\
\hline Peer attachment & $\rightarrow$ & Romantic relationships & .532 & .485 & .071 & $7.523^{* * *}$ \\
\hline
\end{tabular}

Note. $N=221$.

${ }^{*} p<.05 .{ }^{* *} p<.01 .{ }^{* * *} p<.001$. 


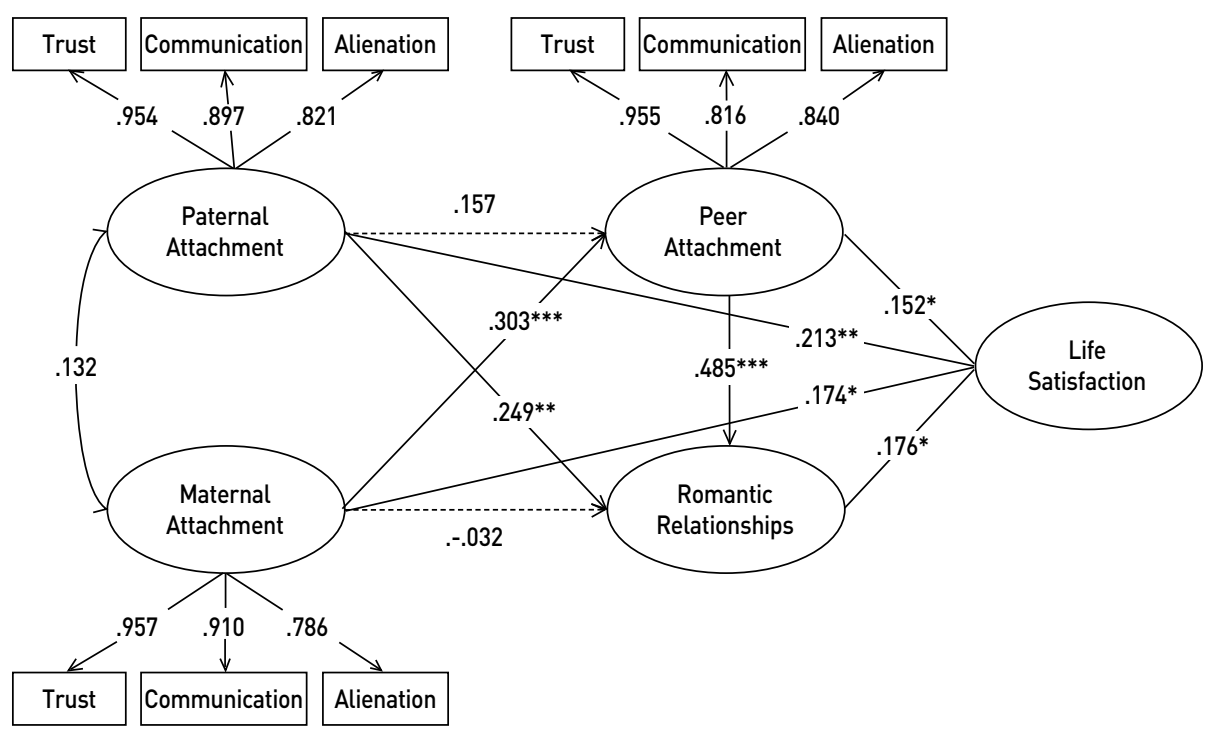

Figure 3. Direct and indirect paths from adolescents' parent attachment to life satisfaction. Measurement errors were deleted. Scores of alienation were reversely coded to match the direction of parent attachment and peer attachment.

${ }^{*} p<.05 .{ }^{* *} p<.01 .{ }^{* * *} p<.001$.

의 만족도에 통계적으로 유의미한 간접적 영향을 미치는 것으 로 나타났다. 또한 부애착 $(\beta=.076, p<.05)$ 과 모애착 $(\beta=.147$, $p<.01)$ 이 이성관계에 미치는 영향과 관련하여 또래애착의 간 접효과가 발견되었으며, 또래애착은 이성관계를 통해 청소년 의 삶의 만족도에 간접적인 영향을 미쳤다 $(\beta=.085, p<.05)$. 즉, 부모애착이 이성관계에 영향을 미치는 데 있어 또래애착 이 부분 매개하였으며, 부모애착이 청소년의 삶의 만족도에 영향을 미치는 데 있어서는 또래애착과 이성관계가 부분 매개 하였다.
마지막으로, 내생변인이 외생변인에 의해 설명되는 다중 상관치(Squared Multiple Correlations [SMC])를 확인하였다. 그 결과, 청소년의 삶의 만족도의 다중상관치는 .300으로 부모애 착, 또래애착 및 이성관계의 청소년의 삶의 만족도에 대한 설 명력은 $30 \%$ 였다. 한편, 청소년의 또래애착의 다중상관치는 .177 로 부모애착은 또래애착을 약 $18 \%$ 설명하였으며, 청소년 의 이성관계의 다중상관치는 .360 으로 부모애착과 또래애착 은 이성관계를 $36 \%$ 설명하였다.

Table 5

Direct, Indirect, and Total Effects in the SEM

\begin{tabular}{llllcc}
\hline \multicolumn{1}{c}{ Path from latent to latent variables } & \multicolumn{3}{c}{ Bootstrapping } \\
\cline { 3 - 5 } Paternal attachment & $\rightarrow$ & Life satisfaction & Direct effect & Indirect effect & Total effect \\
Maternal attachment & $\rightarrow$ & Life satisfaction & $.213^{*}$ & $.082^{* *}$ & $.295^{* *}$ \\
Peer attachment & $\rightarrow$ & Life satisfaction & $.174^{*}$ & $.066^{* *}$ & $.240^{* *}$ \\
Romantic relationships & $\rightarrow$ & Life satisfaction & $.152^{*}$ & $.085^{*}$ & $.237^{* *}$ \\
Paternal attachment & $\rightarrow$ & Peer attachment & $.176^{*}$ & - & $.176^{*}$ \\
Maternal attachment & $\rightarrow$ & Peer attachment & .157 & $.303^{*}$ & .157 \\
Paternal attachment & $\rightarrow$ & Romantic relationships & $.249^{*}$ & $.076^{*}$ & $.303^{* *}$ \\
Maternal attachment & $\rightarrow$ & Romantic relationships & -.032 & $.147^{* *}$ & $.325^{* *}$ \\
Peer attachment & $\rightarrow$ & Romantic relationships & $.485^{* *}$ & -115 & .360 \\
\hline
\end{tabular}

Note. $N=221$.

${ }^{*} p<.05 .{ }^{* *} p<.01$. 


\section{논의 멫 결론}

본 연구는 고등학교 1-3학년에 재학 중인 청소년을 대상으로 부모애착과 또래애착 및 이성관계가 청소년의 삶의 만족도에 어떠한 경로로 영향을 미치는지를 살펴보았다. 구체적으로, 본 연구는 부애착과 모애착이 청소년의 삶의 만족도에 미치는 직접적 영향과 또래애착 및 이성관계를 통한 간접적 영향을 살펴보았다. 본 연구의 연구문제를 중심으로 주요결과를 요약 하고 논의하면 다음과 같다.

첫째, 부모애착은 청소년의 삶의 만족도에 직접적인 영향 을 미쳐, 청소년은 아버지에 대한 애착과 어머니에 대한 애착 을 높게 지각할수록 자신의 삶의 만족도를 높게 보고하였다. 본 연구의 결과는 부애착과 모애착이 중.고등학생의 생활만족, 심리적 안녕감 및 주관적 안녕감에 영향을 미치는 선행 요인 임을 밝힌 연구결과들(S.-H. Cho \& Jin, 2015; Ko, 2008; Yoo et al., 2006)과 일치한다. 뿐만 아니라 부모애착이 청소년의 적응 과 밀접한 관련이 있다는 선행 연구결과들(Cotterell, 1992; Ma \& Huebner, 2008; Raja et al., 1992)과도 맥을 같이한다. 이러한 연구결과는 청소년의 요구에 대해 부모가 긍정적으로 반응하 고 청소년이 부모와 원활한 의사소통을 하며 부모와 정서적으 로 가깝다고 느낄 때 자신의 삶에 대해 긍정적인 느낌과 감정 을 지님을 의미한다. 청소년기라는 발단단계 특성상 대인관계 의 폭이 넓어지며 이전보다는 상대적으로 부모와 상호작용하 는 시간이 줄어듦에도 불구하고 부모는 청소년의 삶에서 여전 히 중요한 역할을 수행한다는 것을 알 수 있다.

이와 같이, 본 연구에서 부애착과 모애착이 모두 청소년의 삶의 만족도에 유의한 영향을 미치긴 하였으나, 모애착에 비 해 부애착이 상대적으로 다소 높은 영향력을 나타낸 점은 흥미 롭다. 이러한 결과는 부애착이 모애착보다 중학생의 심리적 안 녕감에 커다란 영향을 미친다고 보고한 최근의 선행 연구결과 (S.-H. Cho \& Jin, 2015)와 일맥상통하는 것으로, 아버지가 자녀 의 심리사회적 적응을 도울 수 있음을 강조한다. 이는 최근 들 어 아버지의 양육참여가 증가하고 아버지 역할의 중요성이 강 조되고 있는 우리 사회의 변화를 반영하는 것으로 볼 수 있다. 어머니 역할을 강조한 기존의 선행 연구들과 마찬가지로 청소 년에게 주 양육자로서의 어머니 역할이 기본적으로 중요함은 변함이 없으나, 본 연구결과는 어머니 역할에 비해 상대적으로 관심을 덜 받아오던 아버지 역할에 대한 연구자들의 관심을 환 기시킨다. 한편, 본 연구결과와 상반되게, 중학생을 대상으로 한 Ko (2008)에서는 주관적 안녕감의 하위요인으로서 삶의 만 족도에 대해 모애착이 부애착에 비해 보다 더 커다란 영향을
미치기도 하였다. 이처럼 비일관된 연구결과들이 보고되고 있 어, 부애착과 모애착이 청소년의 심리사회적 적응에 미치는 영 향력에 관해서는 지속적인 연구가 필요해 보인다.

둘째, 부모애착 가운데 모애착만이 또래애착을 통해 청소 년의 삶의 만족도에 영향을 미쳐, 청소년은 어머니에 대한 애 착을 높게 지각할수록 또래에 대한 애착 또한 긍정적으로 지 각하였으며, 또래에 대한 애착을 높게 지각할수록 자신의 삶 에 만족한다고 보고하였다. 모애착, 또래애착 및 청소년의 삶 의 만족도 간의 경로를 살펴본 선행 연구가 거의 발견되지 않 아, 본 연구결과를 선행 연구결과와 직접적으로 비교하는 데 는 어려움이 따른다. 다만, 부애착과 모애착 모두를 부모애착 으로 평가하여 또래애착이 부모애착과 청소년의 삶의 만족 도 간의 관계를 부분 매개함을 발견한 선행 연구결과(Ma \& Huebner, 2008)와 부분적으로 일치한다. 그 외, 모애착과 또래 애착 간의 관계와 또래애착과 삶의 만족도 간의 관계 각각을 청소년을 대상으로 살펴본 선행 연구들과 비교해보면, 본 연 구의 결과는 모애착과 또래애착 간의 관련성을 보고한 연구결 과(Joo, 2011)나 또래애착과 삶의 만족도 및 주관적 안녕감 간 의 관련성을 보고한 연구결과들(Kang \& Kim, 2016; Ko, 2008) 과 일치한다. 모애착이 또래애착에 미치는 긍정적 영향은 애 착이론 측면에서 주 양육자인 어머니와 안정애착을 형성한 청 소년이 긍정적인 내적 작동 모델을 발달시켜 또래와도 좋은 관계를 형성하는 것으로 이해할 수 있다. 또한, 또래애착이 삶 의 만족도에 미치는 긍정적 영향은 또래와 원만한 관계를 맺 은 청소년이 자신의 삶에 대한 전반적 만족감 역시 높은 것을 의미하며, 이는 부모와의 관계와 더불어 청소년의 삶에 있어 또 다른 중요한 영역인 또래와의 관계가 그들의 삶의 만족도 를 설명하는 주요한 선행 요인임을 시사한다. Raja 등(1992)이 언급했듯이, 청소년은 또래로부터 부모와는 질적으로 다른 측 면의 지지를 경험할 수 있을 것이다. 청소년기는 발달단계 특 성상 이전 시기에 비해 사회적 관계가 보다 넓어지고 학교에 서 또래와 보내는 시간이 상대적으로 많아지면서 또래관계의 중요성은 더욱 부각된다. 이처럼 우정관계의 중요성이 강조되 는 청소년기에 또래와 원만한 관계를 형성할 수 있도록 부모 와 교사의 관심이 요구되며, 이를 위해 무엇보다 주 양육자인 어머니와 안정적인 애착관계를 유지하는 것이 기초가 되어야 할 것이다.

모애착이 또래애착을 통해 청소년의 삶의 만족도에 영향을 미치는 경로와 달리, 부애착은 또래애착에 영향을 미치지 않 음으로써 세 변인 간 유의한 경로는 발견되지 않았다. 이러한 연구결과는 본 연구와 동일하게 구조방정식 모형을 통해 청 
소년의 부애착 및 모애착과 또래애착 간의 관계를 분석한 선 행 연구결과(Joo, 2011)와 일치한다. 그러나 본 연구결과와 관 련하여, 구조방정식 모형을 이용한 분석에서는 부애착이 또래 애착에 영향을 미치지 않았으나, 상관관계 분석에서는 부애착 과 모애착의 각 하위요인들이 또래애착의 각 하위요인들과 모 두 유의한 상관을 보인 점은 고려해 볼 만하다. 이는 청소년의 부애착 및 모애착과 또래애착 간에 유의한 상관을 밝힌 연구 결과들(J.-Y. Hong \& Doh, 2002; Ko, 2008)과 일치하는 것으로, 본 연구에서는 부애착과 모애착을 동시에 고려함으로써 부애 착의 영향력이 모애착에 비해 상대적으로 저하되었을 가능성 도 배제할 수 없다.

셋째, 부모애착 가운데 부애착만이 이성관계를 통해 청소 년의 삶의 만족도에 영향을 미쳐, 청소년은 아버지에 대한 애 착을 높게 지각할수록 이성관계의 질을 높게 지각하였으며, 이성관계의 질이 높을수록 자신의 삶에 만족한다고 응답하였 다. 부애착, 이성관계 및 삶의 만족도 간의 관계를 청소년을 대 상으로 살펴본 경우가 드물어 선행 연구결과와 직접적으로 비 교하기는 쉽지 않으나, 본 연구의 결과는 대학생이나 미혼의 성인을 대상으로 아버지와의 관계와 이성관계 간, 그리고 이 성관계와 삶의 만족도 간 관계를 살펴본 몇몇 선행 연구결과 들과 유사하다. 예를 들어, 질적 접근을 통해 어린 시절 아버지 와의 관계가 미혼 여성의 연애 경험에 미치는 영향력을 밝힌 A.-R. Cho와 Oh (2014)는 청소년이 지각한 아버지와의 안정 적 애착이 이성교제 상대와의 긍정적 관계에 영향을 미친 본 연구결과와 일맥상통한다. 이러한 결과는 원만한 이성관계 발 달을 위해 아버지 역할이 중요함을 강조한다. 즉, 어린 시절부 터 아버지는 어머니와 달리 독특하면서도 어머니와 상호보완 적인 역할을 수행하며 자녀의 사회화를 담당하고(Langlois \& Downs, 1980) 자녀의 성역할 발달에도 기여하여(Ha \& Park, 2011; Jeong \& Choi, 1995), 이후 자녀가 이성교제의 상대를 선 택하거나 이성친구와의 관계를 발달시키는 데 영향을 주는 것 으로 해석할 수 있다. 또한, 대학생을 대상으로 한 연구들에서 이성관계의 질은 그들의 행복을 예측하고(Demir, 2008), 이성 친구와의 관계에서 안정적 애착을 형성한 대학생은 스트레스 를 덜 받고 덜 외로워하며 학업적으로 더 만족하는 등 전반적 안녕감이 높았던 점(Moore \& Leung, 2002)과 유사하게, 본 연 구에서 청소년의 경우에도 이성관계의 질이 높을수록 삶의 만 족도가 높게 나타났다. 이러한 결과는 점차 이성친구에게 관 심을 보이며 이성관계를 형성하기 시작하는 시기인 청소년기 에, 앞서 살펴본 부모나 또래 외에 이성친구가 청소년의 삶에 의미 있는 대상이 될 수 있음을 의미한다. 이는 초기 청소년의
경우 부모, 형제, 또래, 이성친구 가운데 상호의존적이고 친밀 한 관계의 대상으로 어머니를 선택한 경우가 가장 많았던 반 면, 후기 청소년은 이성친구를 선택한 경우가 가장 많았던 연 구결과(Laursen \& Williams, 1997)와 동일한 맥락이다. 이처럼 이성친구의 존재는 청소년의 발달에 긍정적 역할을 수행할 수 도 있겠으나, 다른 한편으로는 일탈행동이나 비행과 같은 행 동적 부적응에 영향을 미칠 수도 있다(W.-B. Ahn et al., 2002). 따라서 부모나 교사는 청소년의 이성교제에 관심을 가지고 이 성친구와 올바른 관계를 형성하며 이성교제가 일탈행동으로 이어지지 않도록 지도·감독할 필요가 있다.

본 연구에서 부애착의 경우와 달리 모애착은 이성관계에 영향을 미치지 않아, 모애착, 이성관계 및 청소년의 삶의 만족 도 간의 유의한 경로는 발견되지 않았다. 이처럼 구조방정식 모형을 통해 여러 연구변인들을 동시에 고려한 경우에는 부애 착만이 이성관계에 영향을 미쳤으나, 각 변인 간의 개별적 관 계를 고려한 경우에는 부애착과 모애착의 각 하위요인인 신 뢰감, 의사소통 및 소외감이 이성관계와 모두 유의한 상관을 보였다. 이는 연구대상의 연령이나 하위요인별로 다소 차이를 보였지만 대체로 부애착 및 모애착과 청소년의 이성애착 또 는 낭만애착 간의 유의한 상관을 밝힌 연구결과들(Joo, 2011; J. M. Kim \& Jang, 2008)과 유사한 맥락이다. 한편, 대학생을 대 상으로 부애착, 모애착, 심리적 독립, 이성관계 태도 및 정신건 강 간의 경로를 탐색한 선행 연구에서는 본 연구의 결과와 달 리 부애착과 모애착 모두 이성관계 태도에 영향을 미치지 않 는 것으로 나타나, 부애착 및 모애착이 이성관계 태도를 매개 로 정신건강에 영향을 주는 경로를 밝히지 못하였다(J.-Y. Lee $\& \mathrm{Ha}, 2012)$. 이 외에는 부모애착, 이성관계 및 심리사회적 적 응 간의 관계를 살펴본 선행 연구가 매우 드물어 이러한 변인 들 간의 관계를 명확히 확인하기 위한 후속 연구가 요구된다.

넷째, 부모애착 가운데 모애착만이 또래애착과 이성관계를 통해 청소년의 삶의 만족도에 영향을 미쳐, 청소년은 어머니 에 대한 애착을 높게 지각할수록 또래에 대한 애착 역시 높게 보고하였으며 이는 높은 질의 이성관계로 연결될 뿐만 아니 라 궁극적으로는 자신의 삶에 대해 높은 만족도를 보이는 것 으로 이어졌다. 본 연구에서 다룬 네 가지 연구변인들을 모두 고려한 선행 연구를 발견하기는 쉽지 않다. 단지 청소년을 대 상으로 한 국내 연구에서는 부모애착 중 모애착만이 또래애착 을 매개로 낭만애착에 영향을 미쳤는데(Joo, 2011), 이는 모애 착이 또래애착을 통해 이성관계에 미치는 영향을 밝힌 본 연 구의 일부 경로와 일치한다. 이러한 결과들은 애착이론에 근 거한 관점의 위계 모델(Furman \& Simon, 1999)을 지지하는 것 
이다. 다시 말하면, 비록 본 연구가 횡단적 연구설계를 이용하 여 수행되었음에도 불구하고, 모애착이 또래애착을 매개로 이 성관계에 영향을 미치는 경로를 밝힌 본 연구결과는 Simon, Bouchey와 Furman (2000)이 언급한 것처럼 관계를 형성할 때 이전 관계의 경험이 영향을 미치는 것으로 이해할 수도 있을 것이다. 생애 초기의 애착관계를 통해 형성된 내적 작동 모델 은 아동기의 또래관계로 연결되고 이는 다시 청소년기 이후의 이성관계로 이어질 수 있다. 이때 또래관계와 이성관계 간의 경로는 Furman 등(2002)이 설명한 것과 같이 또래관계와 이성 관계 둘 다 수평적 관계로 상호호혜와 상호 간의 친밀감에 기 초하므로 또래관계가 이성관계의 발달에 중요한 역할을 하는 것으로 사료된다. 이는 본 연구에서 부애착, 모애착 및 또래애 착 가운데 또래애착이 이성관계에 미치는 영향력이 가장 크게 나타난 점과도 관련되는 것으로, 또래관계와 이성관계 간의 관련성이 부모-자녀관계와 이성관계 간의 관련성보다 더 크 다는 것을 알 수 있다. 본 연구는 이러한 선행 연구결과들을 보 다 확장하여 모애착이 또래애착과 이성관계를 매개로 청소년 의 삶의 만족도에까지 영향을 미치는 경로를 확인하였다. 이 는 청소년의 심리사회적 발달 및 적응에 있어 청소년이 맺고 있는 다양한 관계, 즉 부모, 또래, 이성친구 등과의 관계가 모 두 중요함을 시사한다. 이 외에도, 본 연구는 청소년에게 의미 있는 대상인 부모, 또래 및 이성친구와의 관계가 서로 어떻게 영향을 주고받으며 청소년의 삶에 대한 전반적인 느낌에 어떠 한 영향을 미치는지 그 경로를 탐색해 봄으로써, 청소년의 심 리사회적 발달 및 적응의 기초로서 부모와의 애착관계의 중요 성을 강조하였다.

결론적으로, 부모애착은 청소년의 삶의 만족도에 직접적 영향을 미칠 뿐만 아니라 또래애착과 이성관계를 통해 간접적 으로도 영향을 미치는 것으로 나타났다. 이때 부애착 및 모애 착이 또래애착과 이성관계를 매개로 청소년의 삶의 만족도에 영향을 미치는 경로에 있어 부애착과 모애착 간의 서로 다른 경로를 확인하였다. 구체적으로 부애착은 이성관계를 통해서 만, 모애착은 또래애착과 이성관계를 통해 청소년의 삶의 만 족도에 영향을 주었다. 이러한 결과를 통해 자녀의 심리사회 적 발달에 대한 아버지와 어머니의 역할이 서로 다를 수 있음 을 알 수 있다. 이와 더불어, 본 연구의 결과는 청소년의 삶의 만족도가 부모나 또래, 이성친구 등 주변의 가까운 사람과의 상호작용의 질에 따라 좌우될 수 있음을 의미한다. 특히, 청소 년의 삶의 만족도와 관련하여 부모애착이 또래애착이나 이성 관계보다 더 커다란 영향력을 지님을 밝힘으로써, 청소년기에 도 여전히 부모의 영향이 상당히 중요함을 시사한다. 따라서
청소년기에도 계속적으로 부모-자녀관계를 강화하도록 노력 해야 할 것이며, 이를 위해 부모교육 프로그램과 같은 중재적 접근이 요구된다. 본 연구에서 부애착, 모애착, 또래애착 및 이 성관계 가운데 부애착은 청소년의 삶의 만족도에 가장 큰 영 향력을 보였다. 이러한 결과는 그동안 어머니에 비해 상대적 으로 관심을 덜 받아온 아버지 역할의 중요성을 강조한다. 뿐 만 아니라, 부모애착 못지않게 또래애착과 이성관계 역시 청 소년의 삶의 만족도에 영향을 미치는 중요한 변인이었다. 따 라서 청소년의 건강한 발달을 위해 의사소통능력이나 정서조 절능력, 친사회성을 기르는 등 또래 또는 이성친구와 긍정적 관계를 맺을수록 있도록 돕는 대인관계 증진 프로그램의 개발 및 실시에도 관심을 기울일 필요가 있다.

본 연구의 제한점과 이를 근거로 한 후속 연구를 위한 제언 은 다음과 같다. 먼저, 본 연구는 횡단적으로 자료를 수집하 였으므로 부모애착, 또래애착 및 이성관계가 청소년의 삶의 만족도에 미치는 영향에 대한 인과적 관계를 밝히는 데 한계 가 있다. 따라서 후속 연구에서는 종단적 접근을 통해 이들 변 인 간의 인과관계를 보다 명확히 파악할 필요가 있다. 다음으 로, 본 연구는 청소년의 지각이 중요하다고 판단되어, 모든 연 구변인들을 자기보고에 의한 질문지법을 사용하여 측정하였 으나, 이로 인해 변인들 간의 관계가 다소 과장되었을 가능성 이 있다. 추후 연구에서는 자기보고식 방법을 사용하더라도 질문지법 외에 면접법 등과 같이 좀 더 다양한 방법으로 측정 하는 것이 바람직할 것이다. 또한, 본 연구는 연구대상 청소년 의 부-자녀관계와 모-자녀관계에 초점을 둠으로써 이성 및 동 성 부모-자녀관계를 고려하지 못하였다. 부모-자녀관계와 이 성관계 간의 관계에서 이성부모 또는 동성부모가 미치는 영향 력의 차이를 보건대(J. M. Kim \& Jang, 2008), 추후 연구에서 는 청소년의 성을 구분하여 성별 분석을 시도할 수도 있을 것 이다. 뿐만 아니라, 최근 들어 이혼 혹은 재혼 가정이 증가하고 있는 추세임을 감안하여, 후속 연구에서는 가족유형이나 가족 구조의 다양성을 고려하는 것도 필요해 보인다. 이 외에, 본 연 구에서는 청소년의 이성관계에 대해 다루며 관계 형성을 위해 최소한 필요하다고 여겨지는 기간으로서 3 개월 이상 이성교 제 중인 청소년들만을 연구대상으로 제한하였다. 아직까지는 청소년의 이성교제 기간과 관련하여 비교할 수 있는 선행 연 구가 드문 편이므로, 청소년의 이성관계에 대한 후속 연구들 을 통해 적절한 이성교제 기간을 확인해볼 필요가 있다.

이러한 제한점에도 불구하고, 본 연구는 다음과 같은 의의 를 지닌다. 청소년이 대부분의 시간을 함께 보내는 부모, 또래, 이성친구 등과의 관계가 청소년의 발달 및 적응에 중요한 영향 
을 미칠 수 있음에도 불구하고 관련 연구가 드문 실정에, 본 연 구는 청소년의 삶의 만족도와 관련하여 청소년의 가까운 관계 를 동시에 고려하였다는 점에서 의의가 있다. 또한, 청소년의 삶의 만족도와 관련하여 부모와의 관계가 중요함을 확인하였 을 뿐만 아니라 특히 아버지와의 애착의 중요성을 강조하였다. 본 연구는 청소년이 행복하고 건강한 삶을 살아가도록 돕기 위 해 무엇보다 그들을 둘러싸고 있는 다양한 관계에 대한 학문적 관심을 환기시키며, 청소년의 삶의 만족도를 높이기 위한 중재 적 노력에 기여할 수 있는 기초 정보를 제공할 것으로 기대한 다.

\section{Acknowledgements}

This study was supported by the National Research Foundation of Korea Grant funded by the Korean Government (NRF2013S1A3A2055259).

\section{Notes}

This article is a part of the first author's master's thesis submitted in 2015 .

\section{Conflict of Interest}

No potential conflict of interest relevant to this article was reported.

\section{References}

\section{In English}

Allen, J. P., McElhaney, K. B., Kuperminc, G. P., \& Jodl, K. M. (2004). Stability and change in attachment security across adolescence. Child Development, 75(6), 1792-1805. doi:10.1111/j.1467-8624.2004.00817.x

Allen, J. P., Moore, C., Kuperminc, G., \& Bell, K. (1998). Attachment and adolescent psychosocial functioning. Child Development, 69(5), 1406-1419. Retrieved from http:// people.virginia.edu/ psykliff/pubs/publications/SR1.pdf
Armsden, G. C., \& Greenberg, M. T. (1987). The inventory of parent and peer attachment: Individual differences and their relationship to psychological well-being in adolescence. Journal of Youth and Adolescence, 16(5), 427-454. doi:10.1007/ BF02202939

Barry, C. M., Madsen, S. D., Nelson, L. J., Carroll, J. S., \& Badger, S. (2009). Friendship and romantic relationship qualities in emerging adulthood: Differential associations with identity development and achieved adulthood criteria. Journal of Adult Development, 16(4), 209-222. doi:10.1007/s10804009-9067-x

Berlin, L. J., \& Cassidy, J. (1999). Relations among relationships: Contributions from attachment theory and research. In J. Cassidy \& P. R. Shaver (Eds.), Handbook of attachment: Theory, research, and clinical applications (pp. 688-712). NY: Guilford Press.

Berndt, T. J., Hawkins, J. A., \& Jiao, Z. (1999). Influences of friends and friendships on adjustment to junior high school. Merrill-Palmer Quarterly, 45(1), 13-41. Retrieved from http://www.jstor.org/stable/23093308

Bowlby, J. (1973). Attachment and loss: Vol. 2. Separation: Anxiety and anger. New York: Basic Books.

Bowlby, J. (1979). The making and breaking of aflectional bonds. London: Routledge.

Collins, N. L., \& Read, S. J. (1990). Adult attachment, working models, and relationship quality in dating couples. Journal of Personality and Social Psychology, 58(4), 644-663. doi:10.1037/0022-3514.58.4.644

Collins, W. A., \& Repinski, D. J. (1994). Relationship during adolescence: Continuity and change in interpersonal perspective. In R. Montemayor, G. R. Adams, \& T. P. Gullotta (Eds.), Personal relationships during adolescence (pp. 7-36). Thousand Oaks, CA: Sage Publications.

Connolly, J. A., \& Johnson, A. M. (1996). Adolescents' romantic relationships and the structure and quality of their close interpersonal ties. Personal Relationships, 3(2), 185-195. doi:10.1111/j.1475-6811.1996.tb00111.x

Cotterell, J. L. (1992). The relation of attachments and supports to adolescent well-being and school adjustment. Journal of Adolescent Research, 7(1), 28-42. doi:10.1177/074355489271003

Demir, M. (2008). Sweetheart, you really make me happy: Romantic relationship quality and personality as predictors of happiness among emerging adults. Journal of Happiness Studies, 9(2), 257-277. doi:10.1007/s10902-007-9051-8

Diener, E., \& Diener, M. (1995). Cross-cultural correlates of life satisfaction and self-esteem. Journal of Personality and Social Psychology, 68(4), 653-663. doi:10.1007/978-90-481-2352$0 \_4$

Dunphy, D. C. (1963). The social structure of urban adolescent peer groups. Sociometry, 26(2), 230-246. doi:10.2307/2785909 
Fassinger, R. E. (1987). Use of structural equation modeling in counseling psychology research. Journal of Counseling Psychology, 34(4), 425-436. doi:10.1037/0022-0167.34.4.425

Fraley, R. C., \& Davis, K. E. (1997). Attachment formation and transfer in young adults' close friendships and romantic relationships. Personal Relationships, 4(2), 131-144. doi:10.1111/j.1475-6811.1997.tb00135.x

Furman, W. (1999). Friends and lovers: The role of peer relationships in adolescent romantic relationships. In W. A. Collins \& B. Laursen (Eds.), Relationships as developmental contexts: The Minnesota Symposium on Child Psychology (Vol. 30, pp. 133-154). Mahwah, NJ: LEA.

Furman, W., \& Simon, V. A. (1999). Cognitive representations of adolescent romantic relationships. In W. Furman, B. B. Brown, \& C. Feiring (Eds.), The development of romantic relationships in adolescence. New York, NY: Cambridge University Press.

Furman, W., Simon, V. A., Shaffer, L., \& Bouchey, H. A. (2002). Adolescents' working models and styles for relationships with parents, friends, and romantic partners. Child Development, 73(1), 241-255. doi:10.1111/1467-8624.00403

Furman, W., \& Wehner, E. A. (1994). Romantic views: Toward a theory of adolescent romantic relationships. In $\mathrm{R}$. Montemayor, G. R. Adams, \& T. P. Gullotta (Eds.), Personal relationships during adolescence (pp. 168-195). Thousand Oaks, CA: Sage Publications.

Furman, W., \& Wehner, E. A. (1997). Adolescent romantic relationships: A developmental perspective. New Directions for Child and Adolescent Development, 78, 21-36. doi: $10.1002 / \mathrm{cd} .23219977804$

Gilman, R. (2001). The relationship between life satisfaction, social interest, and frequency of extracurricular activities among adolescent students. Journal of Youth and Adolescence, 30(6), 749-767. doi:10.1023/A:1012285729701

Gilman, R., \& Ashby, J. S. (2003). A first study of perfectionism and multidimensional life satisfaction among adolescents. The Journal of Early Adolescence, 23(2), 218-235. doi: 10.1177/0272431603023002005

Giordano, P. C. (2003). Relationships in adolescence. Annual Review of Sociology, 29, 257-281. doi:10.1146/annurev. soc. 29.010202 .100047

Giordano, P. C., Cernkovich, S. A., \& Holland, D. D. (2003). Changes in friendship relations over the life course: Implications for desistance from crime. Criminology, 41(2), 293-328. doi:10.1111/j.1745-9125.2003.tb00989.x

Greenberg, M. T., Siegel, J. M., \& Leitch, C. J. (1983). The nature and importance of attachment relationships to parents and peers during adolescence. Journal of Youth and Adolescence, 12(5), 373-386. doi:10.1007/BF02088721

Hazan, C., \& Shaver, P. (1987). Romantic love conceptualized as an attachment process. Journal of Personality and Social Psychology, 52(3), 511-524. doi:10.1037/0022-3514.52.3.511

Laible, D. J., Carlo, G., \& Raffaelli, M. (2000). The differential relations of parent and peer attachment to adolescent adjustment. Journal of Youth and Adolescence, 29(1), 45-59. doi:10.1023/A:1005169004882

Langeveld, J. H., Koot, H. M., Loonen, M. C. B., HazebroekKampschreur, A. A. J. M., \& Passchier, J. (1996). A quality of life instrument for adolescents with chronic headache. Cephalalgia, 16(3), 183-196. doi:10.1046/j.14682982.1996.1603183.x

Langlois, J. H., \& Downs, A. C. (1980). Mothers, fathers, and peers as socialization agents of sex-typed play behaviors in young children. Child Development, 51(4), 1237-1247. doi: $10.2307 / 1129566$.

Laursen, B., \& Williams, V. A. (1997). Perceptions of interdependence and closeness in family and peer relationships among adolescents with and without romantic partners. New Directions for Child and Adolescent Development, 78, 3-20. doi: 10.1002/cd.23219977803

Leung, C. Y.-W., McBride-Chang, C., \& Lai, B. P. Y. (2004). Relations among maternal parenting style, academic competence, and life satisfaction in Chinese early adolescents. The Journal of Early Adolescence, 24(2), 113-143. doi:10.1177/0272431603262678

Leung, J.-P., \& Leung, K. (1992). Life satisfaction, self-concept, and relationship with parents in adolescence. Journal of Youth and Adolescence, 21(6), 653-665. doi:10.1007/ BF01538737

Lieberman, M., Doyle, A.-B., \& Markiewicz, D. (1999). Developmental patterns in security of attachment to mother and father in late childhood and early adolescence: Associations with peer relations. Child Development, 70(1), 202-213. doi:10.1111/1467-8624.00015

Locker, D., Clarke, M., \& Payne, B. (2000). Self-perceived oral health status, psychological well-being, and life satisfaction in an older adult population. Journal of Dental Research, 79(4), 970-975. doi:10.1177/00220345000790041301

Ma, C. Q., \& Huebner, E. S. (2008). Attachment relationships and adolescents' life satisfaction: Some relationships matter more to girls than boys. Psychology in the Schools, 45(2), 177-190. doi: $10.1002 /$ pits. 20288

Man, P. (1991). The influence of peers and parents on youth life satisfaction in Hong Kong. Social Indicators Research, 24(4), 347-365. doi:10.1007/BF00383734

McCormick, C. B., \& Kennedy, J. H. (1994). Parent-child attachment working models and self-esteem in adolescence. Journal of Youth and Adolescence, 23(1), 1-18. doi:10.1007/ BF01537139

Moore, S., \& Leung, C. (2002). Young people's romantic 
attachment styles and their associations with well-being. Journal of Adolescence, 25(2), 243-255. doi:10.1006/ jado.2002.0464

Nickerson, A. B., \& Nagle, R. J. (2004). The influence of parent and peer attachment on life satisfaction in middle childhood and early adolescence. Quality of Life Research on Children and Adolescents, 23, 35-60. doi:10.1007/978-14020-2312-5_3

Nickerson, A. B., \& Nagle, R. J. (2005). Parent and peer attachment in late childhood and early adolescence. The Journal of Early Adolescence, 25(2), 223-249. doi: $10.1177 / 0272431604274174$

Oberle, E., Schonert-Reichl, K. A., \& Zumbo, B. D. (2011). Life satisfaction in early adolescence: Personal, neighborhood, school, family, and peer influences. Journal of Youth and Adolescence, 40(7), 889-901. doi:10.1007/s10964-0109599-1

Papini, D. R., Roggman, L. A., \& Anderson, J. (1991). Earlyadolescent perceptions of attachment to mother and father a test of the emotional-distancing and buffering hypotheses. The Journal of Early Adolescence, 11(2), 258275. doi:10.1177/0272431691112006

Raja, S. N., McGee, R., \& Stanton, W. R. (1992). Perceived attachments to parents and peers and psychological wellbeing in adolescence. Journal of Youth and Adolescence, 21(4), 471-485. doi:10.1007/BF01537898

Roisman, G. I., Booth-LaForce, C., Cauffman, E., \& Spieker, S. (2009). The developmental significance of adolescent romantic relationships: Parent and peer predictors of engagement and quality at age 15. Journal of Youth and Adolescence, 38(10), 1294-1303. doi:10.1007/s10964-0089378-4

Rubin, K. H., Dwyer, K. M., Booth-LaForce, C., Kim, A. H., Burgess, K. B., \& Rose-Krasnor, L. (2004). Attachment, friendship, and psychosocial functioning in early adolescence. The Journal of Early Adolescence, 24(4), 326356. doi:10.1177/0272431604268530

Schneider, B. H., \& Younger, A. J. (1996). Adolescentparent attachment and adolescents' relations with their peers a closer look. Youth \& Society, 28(1), 95-108. doi:10.1177/0044118X96028001004

Simon, V., Bouchey, H., \& Furman, W. (2000). The social construction of adolescents' representations of romantic relationships. In S. Larose \& G. M. Tarabulsy (Eds.), Attachment and development: Vol. 2: Adolescence (pp.301326). Quebec: Les Presses de l'Universite du Quebec. Retrieved from http://www.du.edu/ahss/psychology/ relationship-center/media/documents/publications/simonbouchey-furman-2000.pdf

Steinberg, L., \& Silk, J. S. (2002). Parenting adolescents. In M.
H. Bornstein (Ed.), Handbook of parenting Vol. 1: Children and parenting (2nd ed., pp. 103-133). Mahwah, NJ: Lawrence Erlbaum Associates Publishers. Retrieved from http://dlia.ir/Scientific/e_book/Social_Sciences/The_ Family_Marriage_Women/HQ_755.7_759.92_Parents_ Parenthood_/004568.pdf\#page=144

Steinberg, S. J., Davila, J., \& Fincham, F. (2006). Adolescent marital expectations and romantic experiences: Associations with perceptions about parental conflict and adolescent attachment security. Journal of Youth and Adolescence, 35(3), 314-329. doi:10.1007/s10964-006-9042-9

Suldo, S. M., \& Huebner, E. S. (2004). Does life satisfaction moderate the effects of stressful life events on psychopathological behavior during adolescence? School Psychology Quarterly, 19(2), 93-105. doi:10.1521/ scpq.19.2.93.33313

Trinke, S. J., \& Bartholomew, K. (1997). Hierarchies of attachment relationships in young adulthood. Journal of Social and Personal Relationships, 14(5), 603-625. doi:10.1177/0265407597145002

Wainright, J. L., Russell, S. T., \& Patterson, C. J. (2004). Psychosocial adjustment, school outcomes, and romantic relationships of adolescents with same-sex parents. Child Development, 75(6), 1886-1898. doi:10.1111/j.14678624.2004.00823.x

Wilkinson, R. B. (2004). The role of parental and peer attachment in the psychological health and self-esteem of adolescents. Journal of Youth and Adolescence, 33(6), 479-493. doi:10.1023/B:JOYO.0000048063.59425.20

Zimmer-Gembeck, M. J., Siebenbruner, J., \& Collins, W. A. (2001). Diverse aspects of dating: Associations with psychosocial functioning from early to middle adolescence. Journal of Adolescence, 24(3), 313-336. doi:10.1006/ jado.2001.0410

\section{In Korean}

Ahn, S. M., \& Bang, H. J. (2013). The relationship between explicit and implicit attachment to parent and subjective well-being in male and female university students. The Korean Journal of Woman Psychology, 18(1), 169-190. Retrieved from http://www.riss.kr/link?id=A100632963

Ahn, W.-B., Lee, J.-G., \& Kim, Y.-H. (2002). The comparison of psycho-social environment between adolescents with and without romantic partners. Journal of Korean Home Economics Education Association, 14(2), 53-66. Retrieved from http://www.riss.kr/link?id=A30036176

Cha, J. H., \& Chun, Y.-J. (2002). Relationship between the health of the family of origin and intimacy among the dating couples. Journal of Korean Family Relations, 7(1) 39-57. 
Retrieved from http://www.riss.kr/link?id=A82583011

Chang, S. B., Lee, S. K., \& Jun, E. M. (2002). Strategies to prevent sexual problems in teenage school girls in Korea. Korean Journal of Women Health Nursing, 8(3), 325-334. Retrieved from http://www.happyhaksul.com/ksdata/2434071

Cho, A.-R., \& Oh, J. E. (2014). A qualitative research: Understanding of father-daughter relational experience in romantic relationship of unmarried woman. The Korean Journal of Counseling And Psychotherapy, 26(20), 479-501. Retrieved from http://www.riss.kr/link?id=A100630854

Cho, S.-H., \& Jin, M.-K. (2015). The mediating effects of optimism in the relationship between parental attachment and psychological well-being in adolescents. Asian Journal of Child Welfare and Development, 13(1), 95-112. Retrieved from http://www.riss.kr/link?id=A100426393

Choi, H. I., \& Moon, Y. K. (2013). Impact of community spirits on school adjustment in adolescents. Journal of Community Welfare, 45, 189-209. Retrieved from http://www.riss.kr/ link?id=A99922548

Ha, S.-J., \& Park, S.-Y. (2011). Fathers' parenting attitudes predicting girls' levels of competence: Gender-role stereotypes and internal motivation as mediators. The Korean Journal of Human Development, 18(1), 133-149. Retrieved from http://www.riss.kr/link?id=A82588325

Hong, J.-Y., \& Doh, H.-S. (2002). Parental marital conflict, attachment to parents, and peer relationships among adolescents. Journal of Korean Home Management Association, 20(5), 125-136. Retrieved from http:// www. riss.kr/link?id=A100455356

Hong, S. (2000). The criteria for selecting appropriate fit indices in structural equation modeling and their rationales. Korean Journal of Clinical Psychology, 19(1), 161-177. Retrieved from http://www.riss.kr/link? id=A100628132

Jeong, H. H., \& Choi, K. S. (1995). Father's child-rearing behaviors, children's sex-role taking, children's emotional responses and children's prosocial behavior. Korean Journal of Child Studies, 16(1), 33-47. Retrieved from http://www. riss.kr/link?id=A3034583

Jo, M. H., \& Cha, K. H. (1998). Quality of life for international comparisons. Seoul: Jipmoondang.

Joo, E. (2011). Parent, peer, and romantic attachment of adolescents according to gender and age differences. Korean Journal of Youth Studies, 18(4), 141-171. Retrieved from http://www.riss.kr/link?id=A82583011

Kang, I., \& Kim, C. (2016). A longitudinal study of the effects of peer attachment, life satisfaction on self-regulation learning ability by adolescent. The Korean Journal of Educational Psychology, 30(2), 411-428. Retrieved from http://www.riss. $\mathrm{kr} /$ link?id=A101962262

Kim, E. J., \& Lee, J. Y. (2009). A study on the relationship between parent attachment and peer relationship among adolescents: The mediating effects of depression and conflict-resolving strategies. Korean Journal of Youth Counselling, 17(2), 55-68. Retrieved from http://www.riss. $\mathrm{kr} /$ link?id= A82587203

Kim, G. S. (2011). AMOS 18.0 structural equation modeling analysis. Seoul: Hannarae.

Kim, J. M., \& Jang, J. H. (2008). The relationship between adolescent's parent attachment and romantic attachment from normal and divorced family. Journal of Future Oriented Youth Society, 5(4), 151-172. Retrieved from http://www. riss.kr/link?id=A77015467

Kim, S.-M., \& Nam, C.-Y. (2011). The effects of adolescents' peer attachment and adaptation to school life on sense of community: Focusing on moderating effect of life satisfaction. Journal of Future Oriented Youth Society, 8(4), 225-242. Retrieved from http://www.newnonmun.com/ article $=27217$

Kim, Y.-H., Lee, J.-Y., \& Kim, N.-Y. (2009). Mediating effects of optimism between parents attachment and teenagers worry. The Journal of Child Education, 18(2), 91-104. Retrieved from http://www.riss.kr/link?id= A76377449

Ko, Y.-N. (2008). The relationship among father, mother, peer attachment and subjective well-being in middle school students. The Journal of Yeolin Education, 16(2), 111-131. Retrieved from http://www.riss.kr/link?id= A76441482

Lee, I. S., \& Yoo, Y. J. (1986). An assessment of the validity of the marital satisfaction scale: Mss of Roach, Frazier, Bowden. Journal of Korean Home Management Association, 4(1), 1-14. Retrieved from http://www. riss.kr/link?id=A100454778

Lee, J.-Y., \& Ha, S.-H. (2012). Effects of parental attachment of college students on mental health mediated by psychological separation and risk in intimacy. Korea Journal of Counseling, 13(6), 2821-2837. Retrieved from http:// www.riss.kr/link?id=A100179494

Lee, M. W. (2016, February 18). Children thrown in the battlefield. Sisapress. Retrieved from http://www.sisapress. com/journal/article/147664

Lee, S. S. (2012). A study on the life satisfaction of the Korean elderly according to their preparation for old ages. The Journal of Consumption Culture, 15(4), 43-61. Retrieved from http://www.riss.kr/link?id= A99549573

Lim, J. G. (2013). The effects of social support on life satisfaction among the elderly: Focusing on the difference between rural and urban area. Korean Journal of Social Welfare Research, 38, 217-240. Retrieved from http://www.happyhaksul. $\mathrm{com} / \mathrm{ksdata} / 3236544$

Ministry of Gender Equality and Family. (2012). 2011 national youth survey (Research Report No. 2012-1). Retrieved from http://www.mogef.go.kr/ 
Nam, J., \& Kim, S. (2014). The effect of life satisfaction index of mother who have elementary school student on the children's initiatives. The Journal of Future Education, 4(1), 41-60. Retrieved from http://www.riss.kr/link? $\mathrm{id}=\mathrm{A} 100178432$

Ok, J. (1998). Relationship between attachment security and depression in adolescence: Focusing on the mediating effect of perceived competence (Master's thesis). Retrieved from http://www.riss.kr/link?id=T4458819

Sohn, B. D. (2005). Multi-variate predictors on the depressed mood and suicidal risk among ordinary adolescents and adolescents with learning disabilities. Korean Journal of Youth Studies, 12(1), 207-228. Retrieved from http://kiss. kstudy.com/

Yoo, A. J., Lee, J. S., \& Jung, H. S. (2006). Emotion regulation style and parent attachment: Effects on adolescents' satisfaction with life. Korean Journal of Child Studies, 27(1), 167-181. Retrieved from http://www.riss.kr/ link?id=A100456018

Yoo, A.-J., Lee, J.-S., \& Kim, J.-M. (2005). The Impacts of bodyimage, attachment to parent and peers, and resilience on adolescents' life satisfaction. Journal of Korean Home
Management Association, 23(5), 123-132. Retrieved from http://www.riss.kr/link?id=A353512

Yum, Y. S., Kim, K. M., \& Lee, S. W. (2016). The research of Korean child well-being index and it's international comparison with other OECD countries (Research Report No. 2016-8). Retrieved from The Korea Bhang Jeong Hwan Foundation website: http://www.korsofa.org

\section{ORCID}

Seung Jin Kim

Hyun-Sim Doh

Woon Kyung Lee

Bokyung Park http://orcid.org/0000-0003-2507-7891

http://orcid.org/0000-0002-7393-4520

http://orcid.org/0000-0002-2221-1787

http://orcid.org/0000-0002-8194-1675
Received August 31, 2016

Revision received October 26, 2016

Accepted October 29, 2016 